\title{
Evaluation of Drought Stress Tolerance Based on Selection Indices in Haricot Bean Varieties Exposed to Stress at Different Growth Stages
}

\begin{abstract}
Awoke Wasae
Plant Science Department, Debark University, Gonder, Ethiopia

Correspondence should be addressed to Awoke Wasae; awokewasae@dku.edu.et

Received 6 October 2020; Revised 1 March 2021; Accepted 3 May 2021; Published 1 June 2021

Academic Editor: Mehdi Rahimi

Copyright (c) 2021 Awoke Wasae. This is an open access article distributed under the Creative Commons Attribution License, which permits unrestricted use, distribution, and reproduction in any medium, provided the original work is properly cited.

A pot experiment was conducted at Hawassa University, Ethiopia, with the objectives of identifying relatively drought-tolerant haricot bean varieties and identifying sensitive growth stages of this plant to drought stress based on selection indices under greenhouse conditions. Ten improved haricot bean varieties were subjected to drought stress at vegetative, flowering, and pod setting stages by withholding water for 15 days. Seed yields ( $\mathrm{g}$ plant ${ }^{-1}$ ) under stress (Ysi) and nonstress (Ypi) conditions were recorded, and all indices were calculated for the three drought stress levels (vegetative, flowering, and pod setting) against the yield obtained from the nonstress (Ypi) treatment. Drought intensity indices at vegetative, flowering, and pod setting stages were 0.046, 0.335 , and 0.249 , respectively. Drought stress imposition at the flowering stage resulted in high values of DII, DSI, PYR, and SSPI and low values of DRI, GM, MP, YSI, MRP, REI, and RDI reflecting that flowering is the most sensitive growth stage to drought stress. Low values of DSI, PYR, and SSPI and high values of DRI, GM, MP, YSI, MRP, REI, and RDI for H/dumme, Wajo, and Nasir confirmed that they are tolerant to drought stresses that occur at different growth stages. Those varieties also showed the best mean of rank and low standard deviation. A strong association between Ypi and Ysi was observed under drought stress at the vegetative stage but not under flowering and pod setting stages. Ysi had a positive correlation with DRI, GM, MP, MRP, and REI while a significant and negative correlation with PYR and DSI depicting that they are a better predictor of potential yield under a stress condition and they can use as a morphological marker by the plant breeder.
\end{abstract}

\section{Introduction}

Haricot bean (Phaseolus vulgaris L.) is an important legume crop grown worldwide. It was most likely introduced to Ethiopia by the Portuguese in the sixteenth century. Haricot bean is grown in central, southern, eastern, and western lowlands and mid-altitudes (1400-2000 m.a.s.l) of Ethiopia as a food and cash crop and produced predominantly by smallholder producers $[1,2]$. The current national average yield of haricot bean is $1.822 \mathrm{t} / \mathrm{ha}$ with total bulk production of $172,739 \mathrm{t} / \mathrm{ha}$ (CSA, 2019/20), which is a low yield as compared to the yield obtained from the national research center $(2.5-3.6 \mathrm{t} / \mathrm{ha})$ [1].

Drought stress at different growth stages and growth of local and obsolete varieties are the most important factors for the low production status in Ethiopia. Drought is the most important factor limiting the productivity of rain-fed production of different pulse crops in southern Ethiopia [3]. It is also considered as the single most devastating environmental stress, which decreases crop productivity more than any other environmental stress combined $[4,5]$. Most of the haricot bean growing regions have erratic rainfall distribution and sandy soil with a low moisture-holding capacity [6]. Even if there is an adequate average annual rainfall in Ethiopia, the production of a sustainable and reliable food supply is becoming very difficult due to temporal and spatial imbalance in the distribution of rainfall and recurrent shortage of water at the required period. Often, crop failure occurs because of the unavailability of water at some critical growth stages $[7,8]$. Varieties also differ in yield as well as for their response to drought stress and other environmental 
constraints, when they are exposed to drought stress at different growth stages [9-11].

As conventional plant breeding solely relies on a morphological marker, there is a need to identify phenotypic traits which reflect the genotype. Furthermore, drought tolerance is a complex and quantitative trait, involving several morphological and physiological characters. As a result, effective breeding of drought-tolerant haricot bean varieties requires good selection criteria to identify droughttolerant genotypes. Darkwa et al. [12] reported the presence of genotypic variability for drought susceptibility index (DSI) in haricot bean varieties. The existence of genotypic variability for drought resistance index (DRI) had also been reported Zarei et al. [13] in wheat and Darkwa et al. [12] in haricot bean. The varietal difference in geometric mean (GM) and mean productivity (MP) had been reported in different crops [14-16]. Furthermore, genotypic variability in wheat for stress tolerance index (STI) was reported at the seedling stage [17, 18]. Kharrazi et al. [19] also reported the presence of difference in performance on exposure of seven sorghum genotypes to drought stress at the panicle initiation stage. Incidentally, further study is required in legume specifically in haricot bean on the use of selection indices to screen well-performed varieties under the stress condition.

Drought indices which provide a measure of drought based on loss of yield under drought conditions in comparison to normal conditions have been used for screening drought-tolerant genotypes [20]. Different drought tolerance index methods have been developed by scientists as a selection criterion. Yield Stability Index (YSI) was suggested by Bouslama and Schapaugh [21] in order to evaluate the stability of varieties in both stress and nonstress conditions. Fischer and Maurer [22] proposed a stress susceptibility index (SSI) of the cultivar. Rosielle and Hamblin [23] defined stress tolerance (TOL) as the differences in yield between the stress (Ys) and nonstress ( $\mathrm{Yp}$ ) environments and mean productivity (MP) as the average yield of Ys and Yp. Drought susceptibility of a genotype is often measured as a percentage of yield reduction in yield under drought stress [24]. Other indices such as abiotic tolerance index (ATI) [25], drought tolerance efficiency (DTE) [26], mean relative performance (MRP) [27], relative drought index (RDI) [26], relative efficiency index (REI) [27], stress susceptibility index (SSI) [22], stress tolerance index (STI) [23], yield index (YI) [28], and coefficient of regression (CR) [29] were also suggested to screen drought tolerant varieties. Therefore, this study was conducted with the objective of (i) evaluating the performance of different haricot bean varieties to drought stress tolerance using selection indices, (ii) identifying the sensitive growth stages of haricot bean to drought stress using selection indices, and (iii) identifying selection indices which are correlated with yield under both stress and nonstress conditions.

\section{Materials and Methods}

2.1. Haricot Bean Varieties and Drought Stress Level. The study was conducted on ten improved varieties of haricot bean (SER-119, Tatu, SAB-632, SER-115, Kat-B9, H/dumme,
Ibbado, Wajo, Nasir, and Red-Wolaita) released in different years by South Agricultural Research Institute (SARI) and Melkassa Agricultural Research Center (MARC) in Ethiopia. Four drought stress levels, namely, full irrigation, drought stress at vegetative, flowering, and pod setting stages for 15 days, were applied. As explained by Fernandez [30], the drought stress was initiated at three developmental stages: (i) at the first compound leaf stage, i.e., when the first trifoliate leaf appears open and flat on $50 \%$ of the plants; (ii) at flowering stage, i.e., when the first open flower appears by $50 \%$ of the plants; and (iii) at pod setting stage, i.e., when $50 \%$ of the plants show the first pod with the corolla of the flower hanging or detached from a crop.

2.2. Experimental Design and Procedures. The experiment was carried out in a greenhouse using a $4 \times 10$ factorial experiment laid out in a split-plot design and three replications with drought stress constituting main plots and varieties as subplots. A wooden bench was constructed inside of the greenhouse so that all pots laid on it. A thermometer was also installed to measure daily internal temperature. Plastic pots with 20-liter capacity perforated at the bottom were filled with topsoil collected up to $30 \mathrm{~cm}$ depth from Hawassa University College of Agriculture Research field. Six seeds of each haricot bean variety were planted in each pot, and two weeks after sowing, the seedlings were thinned to three per pot. All pots were well watered with a three-day interval until the commencement of drought stress treatments. One day before starting the treatments, soil moisture in each pot was maintained to field capacity for the purpose of keeping uniform soil moisture at each pot. At the first compound leaf stage, irrigation was completely cut off for vegetative stress treatment for 15 days, and then, normal irrigation was applied. The same procedure was employed when the plant reached flowering and pod setting stages. The amount of water to be applied was determined by measuring the soil moisture content using Delta-T-Device, Model HH2, which was installed at $12 \mathrm{~cm}$ depth inside pots, and watering was done based on root zone depletion as explained by FAO [31].

$$
\operatorname{Dr}=\mathbf{W r}(\mathbf{f} \mathbf{c})-\mathbf{W r}(\mathbf{t})=1000(\boldsymbol{\theta f} \mathbf{c}-\boldsymbol{\theta t}) \mathrm{Z},
$$

where Dr is the root zone depletion $(\mathrm{mm}), \mathrm{Wr}(\mathrm{fc})$ is the soil water content of the root zone at field capacity $(\mathrm{mm}), \mathrm{Wr}(t)$ is the soil water content of the root zone expressed as depth $(\mathrm{mm}), \theta \mathrm{fc}$ is the volumetric water content at field capacity $(\mathrm{m} 3 / \mathrm{m} 3), \theta t$ is the volumetric water content in the root zone $(\mathrm{m} 3 / \mathrm{m} 3)$, and $Z$ is the effective rooting depth $(\mathrm{m})$.

2.3. Data Collected. Seed yield $\left(\mathrm{g} \mathrm{plant}^{-1}\right)$ under stress and nonstress conditions were recorded on a plant basis and adjusted to $10 \%$ standard grain moisture content of pulse. Drought stress tolerance indices like drought intensity index (DII), drought susceptibility index (DSI), drought tolerance index (DTI), percentage of yield reduction due to drought $(P Y R)$, geometric mean (GM), mean productivity (MP), yield stability index (YSI), mean relative performance (MRP), 
relative efficiency index (REI), relative drought index (RDI), and stress susceptibility percentage index (SSPI) were calculated to screen tolerant varieties and to identify sensitive growth stages to drought stress according to the formula given hereinafter. The methods of each index were calculated for the three drought stress levels (vegetative, flowering, and pod setting) against the yield obtained from the full irrigation treatment.

Rank was given for each variety based on individual selection indices values. The mean of rank was calculated for each variety by averaging all selection indices' values for the variety under consideration since the selection of variety based on a single index is contradictory. The standard deviation of rank was calculated as the deviation of each rank from the mean of rank and variety with a low standard deviation of rank considered as best performed [21-27, 32, 33].

$$
\begin{aligned}
\mathrm{DII} & =1-\left(\frac{\mathrm{Ys}}{\mathrm{Yp}}\right), \\
\mathrm{GM} & =(\sqrt{\mathrm{Ypi}} * \mathrm{Ysi}), \\
\mathrm{DTI} & =\frac{(Y s i *(\mathrm{Ysi} / \mathrm{Ypi}))}{\mathrm{Ys}}, \\
\mathrm{DSI} & =\frac{1-(\mathrm{Ysi} / \mathrm{Ypi})}{1-(\mathrm{Ys} / \mathrm{Yp})} \\
\mathrm{PYR} & =\frac{(\mathrm{Ypi}-\mathrm{Ysi})}{\mathrm{Ypi}} * 100, \\
\mathrm{MRP} & =\left(\frac{\mathrm{Ysi}}{\mathrm{Ys}}\right)+\left(\frac{\mathrm{Ypi}}{\mathrm{Yp}}\right), \\
\mathrm{MP} & =\frac{(\mathrm{Ypi}+\mathrm{Ysi})}{2}, \\
\mathrm{REI} & =\left(\frac{\mathrm{Ysi}}{\mathrm{Ys}}\right) *\left(\frac{\mathrm{Ypi}}{\mathrm{Yp}}\right), \\
\mathrm{YSI} & =\left(\frac{\mathrm{Ysi}}{\mathrm{Ypi}}\right), \\
\mathrm{RDI} & =\frac{(\mathrm{Ysi} / \mathrm{Ypi})}{(\mathrm{Ys} / \mathrm{Yp})} \\
& =\left(\frac{\mathrm{Ypi}-\mathrm{Ysi}}{2 \mathrm{Yp}}\right),
\end{aligned}
$$

where Ysi is the average yield of variety $i$ in a stress condition, Ypi is the average yield of the same variety under nonstress condition, Ys is the average yield of all varieties under stress condition, and $\mathrm{Yp}$ is the average yield of all varieties under nonstress condition.

2.4. Physicochemical Properties of the Soil Used for the Experiment. The laboratory soil analysis results showed that the soil has a loam texture and a slightly alkaline $\mathrm{pH}$ of 7.44 which is in the preferred range for haricot bean production. Bulk density (BD) and cation exchange capacity (CEC) of the soil indicated that the soil is good agricultural soil (Table 1).

2.5. Temperature during Crop Growth Period in the Green House. Daily minimum, maximum, and average temperatures during the crop growth period were $17-26^{\circ} \mathrm{C}, 28-41^{\circ} \mathrm{C}$, and $24-32^{\circ} \mathrm{C}$, respectively (Figure 1 ). The daily average temperature was beyond the optimum for the growth of haricot bean varieties. As a result, considerable flower and pod abortion as well as pollen infertility is expected [34].

\section{Results and Discussion}

3.1. Drought Intensity Index (DII). To quantify the severity of drought stress at different growth stages on seed yield, a drought intensity index (DII) was calculated for this experiment. Accordingly, DII was found to be 0.046 (for drought stress at the vegetative stage) which indicates minimal or no stress, 0.335 (for drought stress at the flowering stage) which indicates moderate drought stress, and 0.249 (for drought stress at pod setting stage) which indicates again moderate drought stress. The reason for less value of DII for drought stress at the vegetative stage is that on rewatering the crop had time to make further adjustments in its vegetative growth as well as yield and yield components [35]. However, drought stress imposition during the reproductive stage caused a relatively higher value of DII, since drought stress at this stage causes abortion of flowers and ovules and senescence of flowers and pods, which all have a direct relation with yield. Moderate drought stress has also been reported in haricot beans $[12,36]$. Basically, under moderate stress, varieties with high yield potential can be suitable whereas under severe stress varieties with high drought tolerance and low yield potential would be more beneficial [37].

\subsection{Drought Susceptibility Index (DSI) and Drought Tolerance} Index (DTI). Drought susceptibility index (DSI) was significantly affected by the main effect of variety $(p<0.01)$ and the interaction effect of stress and variety $(p<0.01)$, while the main effect of stress was not significant (Table 2). In the same manner, drought tolerance index (DTI) was significantly affected by the main effect of variety $(p<0.001)$ and the interaction effect of stress and variety $(p<0.001)$, while the main effect of stress was not significant (Table 2).

The highest DSI values were recorded in $\mathrm{H} /$ dumme at the vegetative stage followed by Kat-B9 at the pod setting stage, indicating that they are vulnerable to drought stress at the respective growth stage and adapted to more favorable environments as they gave better yield than the mean under nonstress condition. Varieties like Ibbado at the vegetative stage and SER-125 at the pod setting stage had low DSI values, indicating that they are drought tolerant during those growth stages. Negative DSI values -0.2 and -0.5 were recorded by Tatu and Red-Wolaita, respectively, reflecting 
TABLE 1: Some physical and chemical properties of the soil used for the experiment.

\begin{tabular}{lcccccccc}
\hline \multicolumn{2}{l}{$\begin{array}{l}\text { Particle size (\%) } \\
\text { Sand }\end{array}$} & Silt & Clay & $\begin{array}{c}\text { pH } \\
1: 2: 5 \mathrm{H}_{2} \mathrm{O}\end{array}$ & $\begin{array}{c}\text { FC } \\
\%\end{array}$ & $\begin{array}{c}\text { PWP } \\
\%\end{array}$ & $\begin{array}{c}\text { BD } \\
\mathrm{g} / \mathrm{cm}^{3}\end{array}$ & $\begin{array}{c}\text { Om } \\
\%\end{array}$ \\
\hline 48.23 & 33.13 & 18.64 & 7.44 & 21.41 & 10.53 & 1.19 & 1.67 & $\mathrm{meq} / 100 \mathrm{gm}$ \\
\hline
\end{tabular}

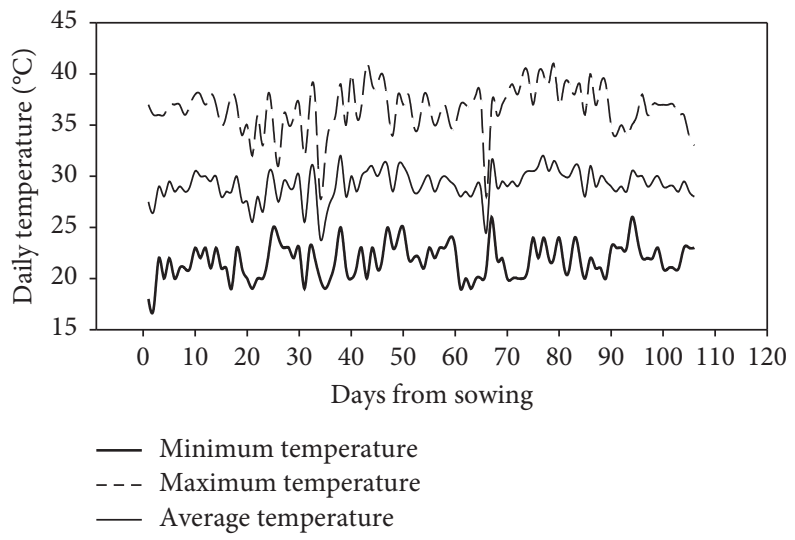

FIGURE 1: Daily minimum, maximum, and average temperatures during the crop growth period.

TABLE 2: Mean squares of ANOVA for evaluation of drought stress tolerance based on selection indices in haricot bean varieties exposed to drought stress at different growth stages.

\begin{tabular}{|c|c|c|c|c|c|c|}
\hline \multirow{2}{*}{ Selection indices } & \multicolumn{6}{|c|}{ Mean square and level of significance for each source of variation } \\
\hline & $\operatorname{Rep} d f=2$ & Stress $d f=2$ & Variety $d f=9$ & Stress $*$ variety $=18$ & Error a $\mathrm{df}=4$ & Error bdf $=54$ \\
\hline Ysi & $0.012^{\mathrm{NS}}$ & $0.602^{* *}$ & $0.096^{* * *}$ & $0.045^{* * *}$ & 0.006 & 0.009 \\
\hline DSI & $1.114^{\mathrm{NS}}$ & $0.025^{\mathrm{NS}}$ & $2.157 *$ & $2.891^{* *}$ & 0.856 & 0.893 \\
\hline DTI & 0.041 NS & $1.708^{\mathrm{NS}}$ & $0.190^{* * *}$ & $0.141^{* * *}$ & 0.021 & 0.018 \\
\hline PYR & $124.269^{\mathrm{NS}}$ & $6015.721^{* *}$ & $966.075^{* * *}$ & $454.186^{* * *}$ & 58.163 & 95.13 \\
\hline GM & $4.970^{\mathrm{NS}}$ & $111.344^{* *}$ & $159.004^{* * *}$ & $9.821^{* * *}$ & 2.088 & 1.649 \\
\hline MP & $3.828^{\mathrm{NS}}$ & $82.626^{* * *}$ & $167.899^{* * *}$ & $7.076^{* * *}$ & 1.338 & 1.316 \\
\hline YSI & $0.012^{\mathrm{NS}}$ & $0.602^{* *}$ & $0.096^{* *}$ & $0.045^{* * *}$ & 0.006 & 0.009 \\
\hline MRP & $0.049^{\mathrm{NS}}$ & $3.96^{\mathrm{NS}}$ & $1.63^{* * *}$ & $0.086^{* * *}$ & 0.019 & 0.017 \\
\hline REI & $0.058^{\mathrm{NS}}$ & $0.005^{\mathrm{NS}}$ & $1.816^{* * *}$ & $0.098^{* * *}$ & 0.034 & 0.019 \\
\hline RDI & $0.021^{\mathrm{NS}}$ & $0.004^{\mathrm{NS}}$ & $0.202^{* * *}$ & $0.088^{* * *}$ & 0.009 & 0.018 \\
\hline SSPI & $37.887^{\mathrm{NS}}$ & $1656.225^{* *}$ & $404.243^{* * *}$ & $141.847^{* * *}$ & 26.824 & 24.700 \\
\hline
\end{tabular}

${ }^{\mathrm{NS}}$ Nonsignificant; * significant; ${ }^{* *}$ highly significant; ${ }^{* * *}$ very highly significant.

that they are high yielder in drought stress than nonstress (Table 3). The response of varieties also differs depending on the stage of drought stress commencement. H/dumme had high DSI values during stress at the vegetative stage but low during the flowering and pod setting stage and vice versa is true for Red-Wolaita (Table 3). The reason for this is that during drought stress at the vegetative stage, varieties that have vigorous seedling growth like Ibbado and Tatu were able to protect the evaporation of water from the soil surface. Genotypic variability for DSI had also been reported [12]. During stress at the vegetative growth stage, high DRI values were recorded for Ibbado, Wajo, and Kat-B9 indicating that they are drought tolerant while the lowest values of DRI were recorded for Red-Wolaita. The result was in accordance with Bennani et al. [14] who found that DRI was significantly affected by the level of drought stress. Furthermore, the existence of genotypic variability for DRI had also been reported $[12,13]$.
3.3. Percentage of Yield Reduction (PYR) and Yield Stability Index (YSI). The main effects of stress, variety, and the interaction effect significantly $(p<0.001)$ affected the percentage of yield reduction (PYR) and yield stability index (YSI) (Table 2). Accordingly, the highest PYR was recorded for Red-Wolaita (55.3\%), Kat-B9 (50.5\%), and Ibbado (49.7\%) when drought stress was initiated during the flowering stage indicating that the varieties are not drought tolerant and flowering is the most sensitive growth stage (Table 3). In accordance with the present study, scholars found that there is the highest PYR when drought stress is imposed at the flowering stage [38, 39]. Negative PYR for Tatu $(-0.99 \%)$ and Red-Wolaita $(-2.48 \%)$ indicated that they gave better yield under the drought stress condition than nonstress condition (Table 3). The lowest PYR was recorded for Tatu $(-0.99 \%)$, Red-Wolaita $(-2.48 \%)$, and Ibbado $(0.27 \%)$ at the vegetative stage reflecting that they are tolerant to the drought that occurred during the vegetative 
TABLE 3: Seed yield (g plant ${ }^{-1}$ ) under nonstress and drought stress and drought tolerance indices of haricot bean varieties exposed to drought stress at different growth stages.

\begin{tabular}{|c|c|c|c|c|c|c|c|c|c|c|c|c|c|}
\hline \multirow{2}{*}{$\begin{array}{l}\text { Drought } \\
\text { Stress }\end{array}$} & \multirow[b]{2}{*}{ Varieties } & \multicolumn{12}{|c|}{ Drought tolerance indices } \\
\hline & & Ypi & Ysi & DSI & DTI & PYR & GM & MP & YSI & MRP & REI & RDI & SSPI \\
\hline \multirow{10}{*}{$\begin{array}{l}\text { Drought stress at } \\
\text { vegetative stage }\end{array}$} & SER-119 & 17.79 & 17.74 & 0.06 & 0.83 & 0.27 & 17.77 & 17.77 & 1 & 1.63 & 0.66 & 1.05 & 0.11 \\
\hline & Tatu & 17.55 & 17.72 & -0.2 & 0.84 & -0.99 & 17.63 & 17.63 & 1.01 & 1.62 & 0.65 & 1.06 & -0.38 \\
\hline & SAB-632 & 21.01 & 19.8 & 1.25 & 0.88 & 5.77 & 20.4 & 20.41 & 0.94 & 1.87 & 0.87 & 0.99 & 2.71 \\
\hline & SER-125 & 15.13 & 14.63 & 0.71 & 0.66 & 3.27 & 14.88 & 14.88 & 0.97 & 1.36 & 0.47 & 1.01 & 1.12 \\
\hline & Kat-B9 & 27.1 & 25.27 & 1.46 & 1.11 & 6.75 & 26.17 & 26.18 & 0.93 & 2.4 & 1.44 & 0.98 & 4.1 \\
\hline & $\mathrm{H} /$ dumme & 22.69 & 18.09 & 4.38 & 0.68 & 20.3 & 20.26 & 20.39 & 0.8 & 1.86 & 0.86 & 0.84 & 10.3 \\
\hline & Ibbado & 30.45 & 30.37 & 0.06 & 1.42 & 0.27 & 30.41 & 30.41 & 1 & 2.79 & 1.94 & 1.05 & 0.18 \\
\hline & Wajo & 30.57 & 28.7 & 1.32 & 1.27 & 6.1 & 29.62 & 29.64 & 0.94 & 2.72 & 1.84 & 0.98 & 4.19 \\
\hline & Nasir & 21.37 & 20.51 & 0.87 & 0.92 & 4.05 & 20.94 & 20.94 & 0.96 & 1.92 & 0.92 & 1.01 & 1.92 \\
\hline & $\begin{array}{c}\text { Red- } \\
\text { Wolaita }\end{array}$ & 19.71 & 20.2 & -0.5 & 0.97 & -2.48 & 19.95 & 19.95 & 1.02 & 1.83 & 0.84 & 1.07 & -1.1 \\
\hline \multirow{10}{*}{$\begin{array}{l}\text { Drought stress at } \\
\text { flowering stage }\end{array}$} & SER-119 & 17.79 & 10.86 & 1.16 & 0.45 & 38.9 & 13.9 & 14.33 & 0.61 & 1.53 & 0.58 & 0.92 & 15.5 \\
\hline & Tatu & 17.55 & 13.92 & 0.62 & 0.74 & 20.7 & 15.63 & 15.73 & 0.79 & 1.72 & 0.74 & 1.19 & 8.12 \\
\hline & SAB-632 & 21.01 & 11.28 & 1.38 & 0.41 & 46.3 & 15.4 & 16.15 & 0.54 & 1.7 & 0.71 & 0.81 & 21.8 \\
\hline & SER-125 & 15.13 & 14.1 & 0.2 & 0.89 & 6.78 & 14.61 & 14.62 & 0.93 & 1.63 & 0.64 & 1.4 & 2.31 \\
\hline & Kat-B9 & 27.1 & 13.41 & 1.51 & 0.45 & 50.5 & 19.06 & 20.25 & 0.49 & 2.12 & 1.1 & 0.74 & 30.6 \\
\hline & $\mathrm{H} /$ dumme & 22.69 & 21.96 & 0.1 & 1.43 & 3.23 & 22.32 & 22.32 & 0.97 & 2.49 & 1.5 & 1.46 & 1.63 \\
\hline & Ibbado & 30.45 & 15.33 & 1.48 & 0.52 & 49.7 & 21.6 & 22.89 & 0.5 & 2.4 & 1.41 & 0.76 & 33.8 \\
\hline & Wajo & 30.57 & 21.38 & 0.9 & 1.01 & 30.1 & 25.56 & 25.97 & 0.7 & 2.81 & 1.97 & 1.05 & 20.6 \\
\hline & Nasir & 21.37 & 17.45 & 0.55 & 0.96 & 18.4 & 19.31 & 19.41 & 0.82 & 2.13 & 1.12 & 1.23 & 8.77 \\
\hline & $\begin{array}{c}\text { Red- } \\
\text { Wolaita }\end{array}$ & 19.71 & 8.82 & 1.65 & 0.27 & 55.3 & 13.18 & 14.26 & 0.45 & 1.48 & 0.52 & 0.67 & 24.4 \\
\hline \multirow{13}{*}{$\begin{array}{l}\text { Drought stress at pod } \\
\text { setting stage }\end{array}$} & SER-119 & 17.79 & 12.02 & 1.29 & 0.49 & 32.4 & 14.62 & 14.91 & 0.68 & 1.51 & 0.57 & 0.9 & 12.9 \\
\hline & Tatu & 17.55 & 15.98 & 0.39 & 0.87 & 8.95 & 16.74 & 16.76 & 0.91 & 1.74 & 0.75 & 1.21 & 3.51 \\
\hline & SAB-632 & 21.01 & 13.63 & 1.53 & 0.53 & 35.1 & 16.92 & 17.32 & 0.65 & 1.75 & 0.76 & 0.86 & 16.5 \\
\hline & SER-125 & 15.13 & 15.02 & 0.03 & 0.89 & 0.69 & 15.08 & 15.08 & 0.99 & 1.57 & 0.61 & 1.32 & 0.25 \\
\hline & Kat-B9 & 27.1 & 15.02 & 1.94 & 0.5 & 44.6 & 20.18 & 21.06 & 0.55 & 2.11 & 1.09 & 0.74 & 27 \\
\hline & $\mathrm{H} /$ dumme & 22.69 & 20.43 & 0.43 & 1.1 & 9.96 & 21.53 & 21.56 & 0.9 & 2.23 & 1.24 & 1.2 & 5.06 \\
\hline & Ibbado & 30.45 & 18.06 & 1.77 & 0.64 & 40.7 & 23.45 & 24.25 & 0.59 & 2.44 & 1.47 & 0.79 & 27.7 \\
\hline & Wajo & 30.57 & 23.43 & 1.02 & 1.07 & 23.4 & 26.76 & 27 & 0.77 & 2.77 & 1.91 & 1.02 & 16 \\
\hline & Nasir & 21.37 & 19.1 & 0.46 & 1.02 & 10.6 & 20.2 & 20.24 & 0.89 & 2.1 & 1.09 & 1.19 & 5.08 \\
\hline & $\begin{array}{c}\text { Red- } \\
\text { Wolaita }\end{array}$ & 19.71 & 14.8 & 1.07 & 0.67 & 24.6 & 17.12 & 17.29 & 0.75 & 1.77 & 0.78 & 1.01 & 10.8 \\
\hline & $\mathrm{SE} \pm$ & 0.720 & 1.087 & 0.546 & 0.078 & 5.631 & 0.741 & 0.662 & 0.056 & 0.075 & 0.08 & 0.077 & 2.869 \\
\hline & Lsd & 0.6455 & 3.1299 & 0.8906 & 0.2215 & 15.726 & 2.1183 & 1.8763 & 0.1573 & 0.2119 & 0.2332 & 0.2132 & 8.1469 \\
\hline & $\mathrm{CV}$ & 5.58 & 12.14 & 102.62 & 19.44 & 49.54 & 6.53 & 5.74 & 12.14 & 6.45 & 13.42 & 13.02 & 47.17 \\
\hline
\end{tabular}

growth stage. High YSI values of Red-Wolaita, Tatu, and SER-119 under drought stress at the vegetative stage mean that they are stable under stress and nonstress conditions. The lowest YSI values were recorded for Red-Wolaita (0.45) and Ibbado (0.5) reflecting that they are susceptible to the drought that occurred at the flowering stage (Table 3).

3.4. Geometric Mean (GM), Mean Productivity (MP), Relative Efficiency Index (REI), and Mean Relative Performance $(M R P)$. Geometric mean (GM) and mean productivity (MP) were significantly $(p<0.001)$ affected by the main effect of stress, variety, and the interaction effect, while relative efficiency index (REI) and mean relative performance (MRP) were affected $(p<0.001)$ only by the use of different varieties and the interaction effect of stress and variety (Table 2). Ibbado and Wajo gave the highest GM, MP, REI, and MRP under drought stress at the vegetative stage, indicating that the two varieties are high yielding under both drought stress and nonstress conditions
(Table 3). The lowest GM, MP, REI, and MRP obtained by Red-Wolaita under drought stress at the flowering stage signify that the variety is more sensitive to drought stress occurring at the flowering stage and flowering is the most sensitive growth stage. Genotypic variability for GM and MP had been reported $[15,16]$. Similar ranks of varieties were observed by GM, MP, REI, and MRP which suggests that these four indices have equal importance for selecting genotypes under stress and nonstress conditions [40].

3.5. Relative Drought Index (RDI) and Stress Susceptibility Percentage Index (SSPI). Variety and the interaction effect of stress and variety significantly $(p<0.001)$ affected the relative drought index (RDI) while the main effect of stress was not significant. Stress susceptibility percentage index (SSPI) was significantly affected by stress $(P<0.05)$, variety $(p<0.001)$, and interaction effect of stress and variety $(p<0.001)$ (Table 2). The highest relative drought index (RDI) was recorded for $\mathrm{H} /$ dumme and Nasir at the flowering 
TABLE 4: Rank (R), mean of ranks (MoR), and standard deviation of ranks (STDRs) of drought tolerance indices of haricot bean varieties exposed to drought stress at different growth stages.

\begin{tabular}{|c|c|c|c|c|c|c|c|c|c|c|c|c|c|c|c|}
\hline \multirow{2}{*}{$\begin{array}{l}\text { Drought } \\
\text { Stress }\end{array}$} & \multirow[b]{2}{*}{ Varieties } & \multicolumn{14}{|c|}{ Drought tolerance indices } \\
\hline & & Ypi & Ysi & DSI & DTI & PYR & GM & MP & YSI & MRP & REI & RDI & SSPI & MoR & STDR \\
\hline \multirow{10}{*}{ Drought stress at vegetative stage } & SER-119 & 8 & 8 & 3 & 8 & 3 & 8 & 8 & 3 & 8 & 8 & 3 & 3 & 5.92 & 2.57 \\
\hline & Tatu & 9 & 9 & 2 & 7 & 2 & 9 & 9 & 2 & 9 & 9 & 2 & 2 & 5.92 & 3.5 \\
\hline & SAB-632 & 6 & 6 & 7 & 6 & 7 & 5 & 5 & 7 & 5 & 5 & 7 & 7 & 6.08 & 0.9 \\
\hline & SER-125 & 10 & 10 & 5 & 10 & 5 & 10 & 10 & 5 & 10 & 10 & 5 & 5 & 7.92 & 2.57 \\
\hline & Kat-B9 & 3 & 3 & 9 & 3 & 9 & 3 & 3 & 9 & 3 & 3 & 8 & 8 & 5.33 & 2.9 \\
\hline & $\mathrm{H} /$ dumme & 4 & 7 & 10 & 9 & 10 & 6 & 6 & 10 & 6 & 6 & 10 & 10 & 7.83 & 2.21 \\
\hline & Ibbado & 2 & 1 & 3 & 1 & 3 & 1 & 1 & 3 & 1 & 1 & 3 & 4 & 2 & 1.13 \\
\hline & Wajo & 1 & 2 & 8 & 2 & 8 & 2 & 2 & 7 & 2 & 2 & 8 & 9 & 4.42 & 3.2 \\
\hline & Nasir & 5 & 4 & 6 & 5 & 6 & 4 & 4 & 6 & 4 & 4 & 5 & 6 & 4.92 & 0.9 \\
\hline & Red-Wolaita & 7 & 5 & 1 & 4 & 1 & 7 & 7 & 1 & 7 & 7 & 1 & 1 & 4.08 & 2.87 \\
\hline \multirow{10}{*}{ Drought stress at flowering stage } & SER-119 & 8 & 9 & 6 & 7 & 6 & 9 & 9 & 6 & 9 & 9 & 6 & 5 & 7.42 & 1.56 \\
\hline & Tatu & 9 & 6 & 4 & 5 & 4 & 6 & 7 & 4 & 6 & 6 & 4 & 3 & 5.33 & 1.67 \\
\hline & SAB-632 & 6 & 8 & 7 & 9 & 7 & 7 & 6 & 7 & 7 & 7 & 7 & 7 & 7.08 & 0.79 \\
\hline & SER-125 & 10 & 5 & 2 & 4 & 2 & 8 & 8 & 2 & 8 & 8 & 2 & 2 & 5.08 & 3.12 \\
\hline & Kat-B9 & 3 & 7 & 9 & 7 & 9 & 5 & 4 & 9 & 5 & 5 & 9 & 9 & 6.75 & 2.26 \\
\hline & $\mathrm{H} /$ dumme & 4 & 1 & 1 & 1 & 1 & 2 & 3 & 1 & 2 & 2 & 1 & 1 & 1.67 & 0.98 \\
\hline & Ibbado & 2 & 4 & 8 & 6 & 8 & 3 & 2 & 8 & 3 & 3 & 8 & 10 & 5.42 & 2.87 \\
\hline & Wajo & 1 & 2 & 5 & 2 & 5 & 1 & 1 & 5 & 1 & 1 & 5 & 6 & 2.92 & 2.07 \\
\hline & Nasir & 5 & 3 & 3 & 3 & 3 & 4 & 5 & 3 & 4 & 4 & 3 & 4 & 3.67 & 0.78 \\
\hline & Red-Wolaita & 7 & 10 & 10 & 10 & 10 & 10 & 10 & 10 & 10 & 10 & 10 & 8 & 9.58 & 1 \\
\hline \multirow{10}{*}{ Drought stress at pod setting stage } & SER-119 & 8 & 10 & 7 & 10 & 7 & 10 & 10 & 7 & 10 & 10 & 7 & 6 & 8.5 & 1.62 \\
\hline & Tatu & 9 & 5 & 2 & 5 & 2 & 8 & 8 & 2 & 8 & 8 & 2 & 2 & 5.08 & 2.97 \\
\hline & SAB-632 & 6 & 9 & 8 & 8 & 8 & 7 & 6 & 8 & 7 & 7 & 8 & 8 & 7.5 & 0.9 \\
\hline & SER-125 & 10 & 6 & 1 & 4 & 1 & 9 & 9 & 1 & 9 & 9 & 1 & 1 & 5.08 & 3.94 \\
\hline & Kat-B9 & 3 & 6 & 10 & 9 & 10 & 5 & 4 & 10 & 4 & 4 & 10 & 9 & 7 & 2.89 \\
\hline & $\mathrm{H} /$ dumme & 4 & 2 & 3 & 1 & 3 & 3 & 3 & 3 & 3 & 3 & 3 & 3 & 2.83 & 0.72 \\
\hline & Ibbado & 2 & 4 & 9 & 7 & 9 & 2 & 2 & 9 & 2 & 2 & 9 & 10 & 5.58 & 3.5 \\
\hline & Wajo & 1 & 1 & 5 & 2 & 5 & 1 & 1 & 5 & 1 & 1 & 5 & 7 & 2.92 & 2.27 \\
\hline & Nasir & 5 & 3 & 4 & 3 & 4 & 4 & 5 & 4 & 5 & 4 & 4 & 4 & 4.08 & 0.67 \\
\hline & Red-Wolaita & 7 & 8 & 6 & 6 & 6 & 6 & 7 & 6 & 6 & 6 & 6 & 5 & 6.25 & 0.75 \\
\hline
\end{tabular}

Ypi=yield under nonstress condition, Ysi=yield under the stress condition, DSI=drought susceptibility index, DTI=drought tolerance index, $\mathrm{PYR}=$ percentage of yield reduction due to drought, $\mathrm{GM}=$ geometric mean, $\mathrm{MP}=$ mean productivity, YSI $=$ yield stability index, $\mathrm{MRP}=$ mean relative performance, REI = relative efficiency index, RDI = relative drought index, SSPI=stress susceptibility percentage index, MoR=mean of ranks, $\mathrm{STDR}=$ standard deviation of rank, $\mathrm{SE} \pm=$ standard error of the mean, Lsd = list significance difference, $\mathrm{CV}=$ coefficient of variation. Maximum and minimum values are indicated in bold.

stage, while the lowest was recorded for Red-Wolaita and Kat-B9 at flowering and pod setting stages, respectively (Table 3). The highest SSPI was recorded for Ibbado and KatB9 under drought stress at the flowering stage and the lowest SSPI was recorded for Tatu and SER-119 under drought stress at the vegetative stage notifying that the flowering stage is most vulnerable to drought compared to vegetative and pod setting stages.

3.6. Ranks of Varieties Based on Drought Tolerance Indices. The rank given for each variety by different tolerance indices' method indicated that the identification of drought-tolerant varieties based on a single criterion was contradictory (Table 4). Different indices introduced different varieties as drought tolerant. To determine the most desirable varieties, the mean of ranks and standard deviation of ranks of all indices were calculated. In consideration of all indices Ibbado, Wajo, and Nasir exhibited the best mean of ranks and almost low standard deviation of rank; hence, they were identified as the most drought-tolerant varieties. However, varieties SER-125, H/dumme, and SAB-632 are the most sensitive varieties to drought stress that occurred at the vegetative growth stage (Table 4). Under drought stress at flowering and pod setting stages, the best mean of ranks and low standard deviation of rank were recorded for $\mathrm{H} /$ dumme, Wajo, and Nasir signifying that those varieties are drought tolerant, while SAB-632, Red-Wolaita, SER-119, and Kat-B9 are susceptible to drought stress (Table 4). Likewise, [41] reported the use of the mean of ranks and standard deviation of ranks to identify well-performed varieties according to all indices.

3.7. Correlation of Different Drought Tolerant Indices with Seed Yield. The strong association between Ypi and Ysi depicts that high yield potential under full irrigation conditions does anticipate superior yield under drought stress at the vegetative stage. Therefore, indirect selection for a stress environment based on the performance of fully irrigated conditions would be effective. The result was in agreement with Panthuwan et al. [37] and Rizza et al. [42] who reported 
TABLE 5: Simple correlation analysis among drought tolerance indices for drought stress at the vegetative stage below diagonal and drought stress at the flowering stage above diagonal.

\begin{tabular}{lccccccccccccc}
\hline & Ypi & Ysi & DSI & DTI & PYR & GM & MP & YSI & MRP & REI & RDI & SSPI \\
\hline Ypi & & 0.47 & 0.37 & 0.06 & 0.37 & $0.83^{* *}$ & $0.89^{* *}$ & -0.37 & $0.83^{*}$ & $0.83^{*}$ & -0.37 & $0.65^{*}$ \\
Ysi & $0.96^{* * *}$ & & $-0.60^{*}$ & $0.90^{* *}$ & $-0.60^{*}$ & $0.88^{* *}$ & $0.82^{* *}$ & 0.62 & $0.88^{* *}$ & $0.87^{* *}$ & 0.62 & -0.35 \\
DSI & 0.21 & -0.06 & & $-0.88^{* *}$ & $1^{* * *}$ & -0.20 & -0.1 & $-1^{* * *}$ & -0.19 & -0.18 & $-0.99^{* * *}$ & $0.92^{* * *}$ \\
DTI & $0.87^{* *}$ & $0.97^{* * *}$ & -0.3 & & $-0.90^{* *}$ & 0.60 & 0.5 & $0.88^{* *}$ & 0.6 & 0.59 & $0.88^{* *}$ & $-0.71^{*}$ \\
PYR & 0.21 & -0.06 & $1^{* * *}$ & -0.30 & & -0.20 & -0.10 & $-1^{* * *}$ & -0.19 & -0.18 & $-0.99^{* * *}$ & $0.93^{* * *}$ \\
GM & $0.99^{* * *}$ & $0.99^{* * *}$ & 0.07 & $0.93^{* * *}$ & 0.07 & & $0.99^{* * *}$ & 0.19 & $0.99^{* * *}$ & $0.99^{* * *}$ & 0.19 & 0.13 \\
MP & $0.99^{* * *}$ & $0.99^{* * *}$ & 0.08 & $0.93^{* *}$ & 0.08 & $1^{* * *}$ & & 0.08 & $0.99^{* * *}$ & $0.99^{* * *}$ & 0.08 & 0.24 \\
YSI & -0.20 & 0.06 & $-1^{* * *}$ & 0.30 & $-1^{* * *}$ & -0.10 & -0.1 & & 0.19 & 0.18 & $0.99^{* * *}$ & $-0.93^{* *}$ \\
MRP & $0.99^{* * *}$ & $0.99^{* * *}$ & 0.07 & $0.93^{* * *}$ & 0.07 & $0.99^{* * *}$ & $0.99^{* * *}$ & -0.07 & & $0.99^{* * *}$ & 0.19 & 0.17 \\
REI & $0.98^{* * *}$ & $0.99^{* * *}$ & 0.04 & $0.94^{* * *}$ & 0.04 & $0.99^{* * *}$ & $0.99^{* * *}$ & -0.04 & $0.99^{* * *}$ & & 0.18 & 0.13 \\
RDI & -0.21 & 0.07 & $-0.99^{* * *}$ & 0.29 & $-0.99^{* * *}$ & -0.07 & -0.07 & $0.99^{* * *}$ & -0.07 & -0.04 & & $-0.93^{* *}$ \\
SSPI & 0.31 & 0.03 & $0.99^{* * *}$ & -0.19 & $0.99^{* * *}$ & 0.17 & 0.17 & $-0.99^{* * *}$ & 0.17 & 0.13 & -0.99 \\
\hline
\end{tabular}

*Significant; * highly significant; ${ }^{* * *}$ very highly significant.

TABLE 6: Simple correlation analysis among drought tolerance indices affected by drought stress at pod setting stage.

\begin{tabular}{|c|c|c|c|c|c|c|c|c|c|c|c|c|}
\hline & Ypi & Ysi & DSI & DTI & PYR & GM & MP & YSI & MRP & REI & RDI & SSPI \\
\hline \multicolumn{13}{|l|}{$\overline{Y p i}$} \\
\hline Ysi & 0.61 & & & & & & & & & & & \\
\hline DSI & 0.60 & -0.24 & & & & & & & & & & \\
\hline DTI & 0.05 & $0.81^{* * *}$ & $-0.8^{* *}$ & & & & & & & & & \\
\hline PYR & 0.58 & -0.27 & $1^{* * *}$ & $-0.77^{* *}$ & & & & & & & & \\
\hline GM & $0.91^{* *}$ & $0.88^{* *}$ & 0.23 & 0.45 & 0.21 & & & & & & & \\
\hline MP & $0.94^{* * *}$ & $0.85^{* *}$ & 0.30 & 0.38 & 0.27 & $1^{* * *}$ & & & & & & \\
\hline YSI & -0.60 & 0.27 & $-1^{* * *}$ & $0.77^{* *}$ & $-1^{* * *}$ & -0.20 & -0.30 & & & & & \\
\hline MRP & $0.91^{* *}$ & $0.88^{* *}$ & 0.24 & 0.44 & 0.21 & $0.99^{* * *}$ & $0.99^{* * *}$ & -0.21 & & & & \\
\hline REI & $0.90^{* *}$ & $0.88^{* *}$ & 0.22 & 0.45 & 0.19 & $0.99^{* * *}$ & $0.99^{* * *}$ & -0.19 & $0.99^{* * *}$ & & & \\
\hline RDI & $-0.58^{*}$ & 0.26 & $-0.99^{* *}$ & $0.77^{* *}$ & $-0.99^{* *}$ & -0.20 & -0.27 & $0.99^{* * *}$ & -0.21 & -0.19 & & \\
\hline SSPI & $0.77^{*}$ & -0.03 & $0.95^{* * *}$ & -0.60 & $0.95^{* * *}$ & 0.44 & 0.50 & $-0.95^{* * *}$ & 0.44 & 0.42 & $-0.95^{* * *}$ & \\
\hline
\end{tabular}

$\mathrm{Ypi}=$ yield under nonstress condition, $\mathrm{Ysi}=$ yield under stress condition, DSI $=$ drought susceptibility index, DTI $=$ drought tolerance index, PYR $=$ per centage of yield reduction due to drought, $\mathrm{GM}=$ geometric mean, $\mathrm{MP}=$ mean productivity, $\mathrm{YSI}=$ yield stability index, $\mathrm{MRP}=$ mean relative performance, $\mathrm{REI}=$ relative efficiency index, RDI = relative drought index, SSPI=stress susceptibility percentage index. * Significant; ** highly significant; *** very highly significant.

that, under moderate stress, varieties with high yield potential are suitable. Under stress at the vegetative stage, Ysi is significantly and positively correlated with DTI, GM, MP, MRP, and REI (Table 5). Under stress at the flowering stage, the association between Ypi and Ysi was weak and nonsignificant. This result indicated that since the stress is more severe than that of the vegetative stage, indirect selection for a stress environment based on the performance of fully irrigated conditions would not be effective. The result was in agreement with Gholipouri et al. [43] and Anwar et al. [44] who found a weak association between Ypi and Ysi as the stress gets stronger. Under stress at the flowering stage, Ysi had a significant and positive correlation with DTI, GM, MP, MRP, and REI while a significant and negative correlation with PYR and DSI (Table 5).

This shows that DRI, GM, MP, PYR, and DSI were better predictors of potential yield than YSI under drought stress at the flowering stage. The result was in accordance with Anwar et al. [44] who reported that DRI, GM, and MP were better predictors of potential yield under stress conditions. Under drought stress at the pod setting stage, Ysi had a significant and positive correlation with DTI, GM, MP, MRP, and
REI (Table 6).Ysi=yield under the stress condition, DSI = drought susceptibility index, DTI = drought tolerance index, $\mathrm{PYR}=$ percentage of yield reduction due to drought, $\mathrm{GM}=$ geometric mean, $\mathrm{MP}=$ mean productivity, $\mathrm{YSI}=$ yield stability index, $\mathrm{MRP}=$ mean relative performance, $\mathrm{REI}=$ relative efficiency index, $\mathrm{RDI}=$ relative drought index, SSPI=stress susceptibility percentage index.Ypi = yield under nonstress condition, Ysi = yield under stress condition, DSI = drought susceptibility index, DI = drought tolerance index, PYR = percentage of yield reduction due to drought, $\mathrm{GM}=$ geometric mean, $\mathrm{MP}=$ mean productivity, $\mathrm{YSI}=$ yield stability index, $\mathrm{MRP}=$ mean relative performance, $\mathrm{REI}=$ relative efficiency index, $\mathrm{RDI}=$ relative drought index, SSPI = stress susceptibility percentage index.

\section{Conclusion and Recommendation}

Drought stress imposed at the flowering stage resulted in high values of DII, DSI, PYR, MRP, REI, and RDI and low values of DTI, GM, MP, YSI, and SSPI reflecting that flowering is the most sensitive growth stage to drought stress as compared to vegetative and pod setting stages; 
consequently, drought could be avoided during the flowering stage. In consideration of all indices, the best mean of ranks and low standard deviation of rank were recorded for $\mathrm{H}$ /dumme, Wajo, and Nasir signifying that those varieties are drought tolerant. A strong association was observed between Ypi and Ysi under full irrigation but not under flowering and pod setting stress. Under drought stress at the flowering stage, Ysi had a significant and positive correlation with DTI, GM, MP, MRP, and REI while PYR, DSI, and YSI negatively correlated with yield reflecting that they are a better predictor of potential yielder variety under a stress condition.

\section{Data Availability}

The data used to support the findings of this study are available from the corresponding author upon request.

\section{Conflicts of Interest}

The author declares no conflicts of interest.

\section{References}

[1] CSA, Agricultural Sample Survey 2019/2020 E.C. Report on Area and Production for Major Crops. Statistical Bullet in Addis Ababa, Ethiopia, CSA, Addis Ababa, Ethiopia, 2019/20.

[2] D. Karanja, S. G. Endire, C. Ruraduma, P. M. Kimani, S. O. Kweka, and B. Louis, Value Added Bean Technologies for Enhancing Food Security, Nutrition, Income and Resilience to Cope with Climate Change and Variability Challenges in Eastern Africa, ILRI, Nairobi, Kenya, 2011.

[3] N. P. Saxena, C. Johansen, M. C. Saxena, and S. N. Silim, Selection for Drought and Salinity Tolerance in Cool-Season Food Legumes, ICARDA, Beirut, Lebanon, 1993.

[4] H. Lambers, F. S. Chapin III, and T. L. Pons, Plant Physiological Ecology, Springer Science \& Business Media, New York, NY, USA, 2008.

[5] H.-B. Shao, L.-Y. Chu, C. A. Jaleel, P. Manivannan, R. Panneerselvam, and M.-A. Shao, "Understanding water deficit stress-induced changes in the basic metabolism of higher plants - biotechnologically and sustainably improving agriculture and the ecoenvironment in arid regions of the globe," Critical Reviews in Biotechnology, vol. 29, no. 2, pp. 131-151, 2009.

[6] B. Simane and P. C. Struik, "Agroclimatic analysis: a tool for planning sustainable durum wheat (Triticum turgidum var. durum) production in Ethiopia," Agriculture, Ecosystems \& Environment, vol. 47, no. 1, pp. 31-46, 1993.

[7] J. G. Benjamin, D. C. Nielsen, and M. F. Vigil, "Quantifying effects of soil conditions on plant growth and crop production," Geoderma, vol. 116, no. 1-2, pp. 137-148, 2003.

[8] K. Demirevska, D. Zasheva, R. Dimitrov, L. Simova-Stoilova, M. Stamenova, and U. Feller, "Drought stress effects on Rubisco in wheat: changes in the Rubisco large subunit," Acta Physiologiae Plantarum, vol. 31, no. 6, p. 1129, 2009.

[9] P. Manjeru, T. Madonzi, B. Makeredza, A. Nciizah, and M. Sithole, "Effects of water stress at different growth stages on yield and yield components of common bean (Phaseolus vulgaris)," African Crop Science, vol. 8, pp. 299-303, 1995.

[10] T. G. Porch, V. H. Ramirez, D. Santana, and E. W. Harmsen, "Evaluation of common bean for drought tolerance in Juana
Diaz, Puerto Rico," Journal of Agronomy and Crop Science, vol. 195, no. 5, pp. 328-334, 2009.

[11] C. S. Wortmann, L. Lunze, V. A. Ochwoh, and J. Lynch, "Bean improvement for low fertility soils in Africa," African Crop Science Journal, vol. 3, no. 4, 1995.

[12] K. Darkwa, D. Ambachew, H. Mohammed, A. Asfaw, and M. W. Blair, "Evaluation of common bean (Phaseolus vulgaris L.) genotypes for drought stress adaptation in Ethiopia," The Crop Journal, vol. 4, no. 5, pp. 367-376, 2016.

[13] L. Zarei, E. Farshadfar, R. Haghparast, R. Rajabi, and M. M. S. Badieh, "Evaluation of some indirect traits and indices to identify drought tolerance in bread wheat (Triticum aestivum L.)," Asian Journal of Plant Sciences, vol. 6, 2007.

[14] S. Bennani, N. Nsarellah, N. Nsarellah, M. Jlibene, W. Tadesse, and H. Ouabbou, "Efficiency of drought tolerance indices under different stress severities for bread wheat selection," Australian Journal of Crop Science, vol. 11, no. 4, pp. 395-405, 2017.

[15] E. Farshadfar, R. Mohammadi, M. Farshadfar, and S. Dabiri, "Relationships and repeatability of drought tolerance indices in wheat-rye disomic addition lines," Australian Journal of Crop Science, vol. 7, no. 1, pp. 130-138, 2013.

[16] H. Moradi, G. A. Akbari, S. K. Khorasani, and H. A. Ramshini, "Evaluation of drought tolerance in corn (Zea mays L.) new hybrids with using stress tolerance indices," European Journal of Sustainable Development, vol. 1, no. 3, p. 543, 2012.

[17] A. Pour-Aboughadareh, A. Etminan, M. Abdelrahman, K. H. M. Siddique, and L.-S. P. Tran, "Assessment of biochemical and physiological parameters of durum wheat genotypes at the seedling stage during polyethylene glycolinduced water stress," Plant Growth Regulation, vol. 92, no. 1, pp. 81-93, 2020.

[18] A. Pour-Aboughadareh, M. Omidi, M. R. Naghavi et al., "Effect of water deficit stress on seedling biomass and physiochemical characteristics in different species of wheat possessing the D genome," Agronomy, vol. 9, no. 9, p. 522, 2019.

[19] M. A. S. Kharrazi and M. R. N. Rad, "Evaluation of sorghum genotypes under drought stress conditions using some stress tolerance indices," African Journal of Biotechnology, vol. 10, no. 61, pp. 13086-13089, 2011.

[20] J. Mitra, "Genetics and genetic improvement of drought resistance in crop plants," Current Science, pp. 758-763, 2001.

[21] M. Bouslama and W. T. Schapaugh, "Stress tolerance in soybeans. I. Evaluation of three screening techniques for heat and drought tolerance 1," Crop Science, vol. 24, no. 5, pp. 933-937, 1984.

[22] R. Fischer and R. Maurer, "Drought resistance in spring wheat cultivars. I. Grain yield responses," Australian Journal of Agricultural Research, vol. 29, no. 5, pp. 897-912, 1978.

[23] A. A. Rosielle and J. Hamblin, "Theoretical aspects of selection for yield in stress and non-stress environment 1," Crop Science, vol. 21, no. 6, pp. 943-946, 1981.

[24] A. Blum, Plant Breeding for Stress Environments, CRC Press, Boca Raton, FL, USA, 1988.

[25] S. S. Mousavi, S. B. Yazdi, M. R. Naghavi, A. A. Zali, H. Dashti, and A. Pourshahbazi, "Introduction of new indices to identify relative drought tolerance and resistance in wheat genotypes," Desert, vol. 12, pp. 165-178, 2008.

[26] R. Fischer and J. Wood, "Drought resistance in spring wheat cultivars. III.Yield associations with morpho-physiological traits," Australian Journal of Agricultural Research, vol. 30, no. 6, pp. 1001-1020, 1979.

[27] A. B. S. Hossain, R. G. Sears, T. S. Cox, and G. M. Paulsen, "Desiccation tolerance and its relationship to assimilate 
partitioning in winter wheat," Crop Science, vol. 30, no. 3, pp. 622-627, 1990.

[28] P. Gavuzzi, F. Rizza, M. Palumbo, R. G. Campanile, G. L. Ricciardi, and B. Borghi, "Evaluation of field and laboratory predictors of drought and heat tolerance in winter cereals," Canadian Journal of Plant Science, vol. 77, no. 4, pp. 523-531, 1997.

[29] K. C. Bansal and S. K. Sinha, "Assessment of drought resistance in 20 accessions of Triticum aestivum and related species I. Total dry matter and grain yield stability," Euphytica, vol. 56, no. 1, pp. 7-14, 1991.

[30] F. Fernandez, P. Gepts, and M. Lopez, Stages Of Development Of The Common Bean Plant; Study Guide To Be Used As A Supplement To The Audio Tutorial Unit On The Same Topic, CIAT, Cali, Colombia, 1986.

[31] FAO, Crop-Water Productivity Model To Simulate Yield Response To Water, FAO, Rome, Italy, 2012.

[32] E. Farshadfar and J. Javadinia, "Evaluation of chickpea (Cicer arietinum L.) genotypes for drought tolerance," Seed and Plant Improvement Journal, vol. 27, no. 4, 2011.

[33] G. C. Fernandez, "Effective selection criteria for assessing plant stress tolerance," in Proceeding of the International Symposium on Adaptation of Vegetables and other Food Crops in Temperature and Water Stress, pp. 257-270, Shanhua, Taiwan, 1992.

[34] K. Suzuki, M. Shono, and Y. Egawa, "Occurrence of abnormal pods and abscission of flowers at high temperatures in snap bean," Res Highlights JIRCAS, pp. 46-47, 2003.

[35] W. Worku and A. O. Skjelvag, "The effect of different moisture and light regimes on productivity, light intercception and use efficiency of common bean," SINET: Ethiopian Journal of Science, vol. 29, no. 2, pp. 95-106, 2006.

[36] A. Asfaw and M. W. Blair, "Quantification of drought tolerance in Ethiopian common bean varieties," Agricultural Sciences, vol. 5, no. 2, 2014.

[37] G. Panthuwan, S. Fukai, M. Cooper, S. Rajatasereekul, and J. C. Toole, "Yield response of rice (Oryza sativa L.) genotypes to different types of drought under rain fed lowlands," Field Crop Resistance, vol. 73, pp. 153-168, 2002.

[38] S. Mahendran and D. C. Bandara, Effects of Soil Moisture Stress at Different Growth Stages on Vitamin C, Capsaicin, Canadian Science Publishing, Ontario, Canada, 2000.

[39] R. Vijitha and S. Mahendran, "Effect of moisture stress at different growth stages of tomato plant (Lycopersicon esculentum Mill.) on yield and quality of fruits," Journal of Science of the University of Kelaniya Sri Lanka, vol. 5, 2012.

[40] M. Akcura and S. Ceri, "Evaluation of drought tolerance indices for selection of Turkish oat (Avena sativa L.) landraces under various environmental conditions," Zemdirbyste-Agriculture, vol. 98, no. 2, pp. 157-166, 2011.

[41] M. R. Naghavi, A. Pour Aboughadareh, and M. Khalili, "Evaluation of drought tolerance indices for screening some of corn (Zea mays L.) cultivars under environmental conditions," Notulae Scientia Biologicae, vol. 5, no. 3, pp. 388-393, 2013.

[42] F. Rizza, F. W. Badeck, L. Cattivelli, O. Lidestri, N. Di Fonzo, and A. M. Stanca, "Use of a water stress index to identify barley genotypes adapted to rainfed and irrigated conditions," Crop Science, vol. 44, no. 6, pp. 2127-2137, 2004.

[43] A. Gholipouri, M. Sedghi, R. S. Sharifi, and N. M. Nazari, "Evaluation of drought tolerance indices and their relationship with grain yield in wheat cultivars," Recent Research in Science and Technology, vol. 1, no. 4, pp. 195-198, 2009.
[44] J. Anwar, G. M. Subhani, M. Hussain, J. Ahmad, M. Hussain, and M. Munir, "Drought tolerance indices and their correlation with yield in exotic wheat genotypes," Pakistan Journal of Botany, vol. 43, no. 3, pp. 1527-1530, 2011. 